\title{
Subjective Quality Assessment in Stereoscopic Video Based on Analyzing Parallax and Disparity
}

\author{
J. P. López, J. A. Rodrigo, D. Jiménez and J. M. Menéndez
}

\begin{abstract}
Disparity may cause visual discomfort. Pairs of video sequences with different levels of parallax, both negative and positive, were presented together to the observers. The observers evaluated the cases in which visual discomfort occurred after visualizing the transition on each pair.
\end{abstract}

\section{INTRODUCTION}

Recent research in the field of audiovisual system carried out by research workgroup "Qualinet" and collected in Qualinet White Paper [1] defines Quality of Experience (QoE) as the user's degree of delight or annoyance with an application or service. That is the main purpose of this paper, defining the QoE when observing a 3DTV content, considering the delight or annoyance in human eye. So, cases where the disparity between left and right view is in the limit of these two concepts have been analyzed when causing visual discomfort.

The work in Quality of Experience for stereoscopic contents could be referred to different research fields: i.e. analysis of disparity, distribution of parallax, motion, encoding process or artifacts detection. This work is specifically focused on the content generation and the quality offered in transitions with abrupt variations in the general disparity of the sequences. Subjective assessment developed with real observers served as the basic methodology to evaluate different types of transitions after subjective assessment processes.

Applications in audiovisual systems where subjective assessment has been used are multiple, above all when it is difficult to find a reference as happens with tablets or smartphones [2]. In 3D stereoscopic television, subjective test are also available for evaluating visual discomfort and other artifacts related to human vision. In [3], an overview describing the main topics relevant to comfort in viewing stereoscopic television is developed, analyzed after subjective tests, related to accommodation-vergence conflict, parallax distribution, binocular mismatches, depth, and cognitive inconsistencies. In [4], it is reported that depth and motion are closely related in terms of calculating visual discomfort. And [5] offers a visual comfort model for detecting salient object's motion features in depth of field. Also, studies developed by $\mathrm{Li}$ and Barkowsky about visual discomfort in stereoscopic 3D video sequences, are included in [6]. An interesting subjective evaluation of visual discomfort is developed in [7]. Parallax limits, regions of comfort, screen size, and also disparity and viewing time are analyzed as main causes of visual discomfort. Shang-Hyun also proposes perceptual maps for evaluating discomfort [8].

After first experiences, collected in our previous research [9], the study attempts to go further, widening our horizons, with more tests and in-depth tests. The added value derived from the tests developed on this paper lies on the analysis of a specific effect not previously analyzed or quantified in other subjective assessment included in the state-of-the-art, which is the consideration of disparity in objects through the picture and its variations in video transitions. The paper distinguishes cases where disparity and parallax changes may cause visual discomfort.

In the following text, we make an overview of the related studies collected in Section I. The definition and description of subjective test are shown in Section II, presenting the conditions and settings. The sequences from the database used are described in Section III, the analysis of results appears in Section IV and in Section $\mathrm{V}$ a conclusion is reached.

\section{SuBJECTIVE ASSESSMENT}

Methodologies for the assessment of picture quality were developed following procedures included in the Recommendation ITU-T P.910 [10] and BT. 2021 [11]. The method used was single-stimulus (SS), since the objective was to evaluate the quality perceived by the observer, while reducing the duration of each individual session. The test sequences were presented only once in the test session, while in the beginning, dummy sequences were presented as a reference for the user, just to make the procedure understandable. Observers taking part in the tests were asked to evaluate the transition between pairs of videos in each sequence. For expressing their disagreement if detecting visual discomfort while watching the change.

TABLE I. LEVELS OF THE SCALE USED IN TESTS

\begin{tabular}{ccc}
$\begin{array}{c}\text { MOS } \\
\text { Scale }\end{array}$ & $\begin{array}{c}\text { Annoyance derived } \\
\text { from transition }\end{array}$ & $\begin{array}{c}\text { Quality of } \\
\text { Experience }\end{array}$ \\
\hline 5 & Very comfortable & Excellent Experience \\
4 & Comfortable & Good Experience \\
3 & Mildly uncomfortable & No visual discomfort \\
2 & Uncomfortable & Visual discomfort \\
1 & Extremely uncomfortable & High visual discomfort \\
\hline \hline
\end{tabular}

TABLE II. BASIC CHARACTERISTICS AND SETTINGS OF DEVICES

\begin{tabular}{ll}
\hline \hline Device & Philips 65PFL9708S \\
Resolution & $3840 \times 2160 \mathrm{p}$ \\
Brightness & $450 \mathrm{~cd} / \mathrm{m}^{2}$ \\
Size & $65 \%$ Widescreen \\
Technology & LED Ultra HD \\
3D & Passive glasses \\
\hline \hline
\end{tabular}

The observers were placed at 2.5 meters from the screen. It is commonly known that the recommended optimum distance 
for HDTV systems varies depending on the desired angle of vision. ITU-T P910 specifies a wide range of distances ranging from 1 to 8 times the height of the screen. A typical recommendation of 1.6 times the screen diagonal offers a $30^{\circ}$ angle. Others prefer an even higher angle of $40^{\circ}$ to increase immersive experience. This means a distance of 1.2 times the screen diagonal. In our tests the viewers were standing at 2.5 meters from the screen, 1.5 times the screen's diagonal $\left(65^{\prime \prime}\right)$.

A total of 72 observers took part in this testing and fulfilled the whole 20 sequences. It is recommended between 4 and 40 observers, but 72 will offer more accuracy to the study. They were previously explained the tests with video sequences as examples. Also their capacity to see $3 \mathrm{D}$ contents was analyzed with sequences to demonstrate their validity for tests. Most participants were male, not only scholars but also faculty staff, mainly led by curiosity to complete the test. A vast majority $(90 \%)$ were considered non-professional observers. Only a small percentage of the tests was carried out by professional observers, used to this kind of assessment. People less than 20 years old and between 20 and 30 years old represent the highest percentage in the sample. Only a small group of people are over 30 years old. Only $3 \%$ of the observers were considered outliers. Their opinions were discarded because their scores were out of the correlation margin.

\section{VIDEO DATABASE AND SESSIONS DESCRIPTION}

Video sequences used for work development were mainly based on stereoscopic database by University of Nantes [12]. Also, synthetic sequences specifically created for this work with specific parallax conditions were used for this study. Professional software for 3D modelling allows obtaining effects of hyperstereoscopy. Finally, other sequences used came from different sources.

The advantage of using virtual cameras for creating synthetic sequences is that it helps to control disparity modifying the distance between left and right cameras, and position of the objects closer or further from the screen.

A session of twenty video sequences was presented to the observers in the subjective assessment tests. Each sequence was composed of two videos, and the users were asked to assess the visual effect provoked by the transition between them.

As mentioned, the method used for the tests was singlestimulus (SS). The observers, in groups of four or five people, are presented each video of a duration between 10 and 30 seconds only once.

Next, the pairs of videos are collected in Table III, describing the reason why they were selected. Most of the cases, each transition represents a variation in type of disparity (mostly in negative parallax environment) in the same or in a different area of the image, with a higher or lower temporal entropy, corresponding to different motion levels.

The selection of videos generating transitions depends on the distribution of parallax and disparity related to position, amount of pixels and type of parallax. Hyperstereoscopy was considered when there are groups of pixels with negative parallax of at least 10 pixels of disparity.

TABLE III. VIDEO SEQUENCES USED IN QUALITY ASSESSMENT, WITH DESCRIPTION OF PERCENTAGE OF PIXELS IN POSITIVE P+ (\%) AND NEGATIVE PARALLAX P-(\%) AND HYPERSTEREOSCOPY (HS).

\begin{tabular}{|c|c|c|c|c|c|c|c|c|}
\hline $\mathbf{S}$ & Video 1 & $\begin{array}{l}\mathrm{P}+ \\
(\%)\end{array}$ & $\begin{array}{l}\text { P- } \\
(\%)\end{array}$ & HS & Video 2 & $\begin{array}{l}\mathbf{P}+ \\
(\%)\end{array}$ & $\begin{array}{l}\text { P- } \\
(\%)\end{array}$ & \\
\hline \multirow[t]{2}{*}{1} & Ladder & 27 & 7 & $\mathrm{Y}$ & Plunger & 30 & 10 & $\mathrm{Y}$ \\
\hline & \multicolumn{8}{|c|}{$\begin{array}{l}\text { Negative parallax in center area of both videos } \\
\text { Video 1: } \mathrm{TI}=20, \mathrm{SI}=50 . \text { Video } 2: \mathrm{TI}=19, \mathrm{SI}=62 \text {. }\end{array}$} \\
\hline \multirow[t]{2}{*}{2} & Boxers & 25 & 15 & $\mathrm{Y}$ & Dance & 24 & 15 & $\mathrm{~N}$ \\
\hline & \multicolumn{8}{|c|}{$\begin{array}{l}\text { See Section V } \\
\text { Video 1: } \mathrm{TI}=19, \mathrm{SI}=50 \text {. Video } 2 \text { : } \mathrm{TI}=16, \mathrm{SI}=44 .\end{array}$} \\
\hline \multirow[t]{2}{*}{3} & Barrier & 27 & 10 & $\mathrm{Y}$ & Basket & 36 & 8 & $\bar{N}$ \\
\hline & \multicolumn{8}{|c|}{$\begin{array}{l}\text { High negative parallax in the right side of first sequence and genera } \\
\text { parallax in the second } \\
\text { Video } 1 \text { : } \mathrm{TI}=21, \mathrm{SI}=59 \text {. Video } 2: \mathrm{TI}=41, \mathrm{SI}=71 \text {. }\end{array}$} \\
\hline \multirow[t]{2}{*}{4} & Hall & 29 & 15 & $\mathrm{Y}$ & $\mathrm{Lab}$ & 33 & 12 & $\mathrm{Y}$ \\
\hline & \multicolumn{8}{|c|}{$\begin{array}{l}\text { See Section } V \\
\text { Video 1: } \mathrm{TI}=5, \mathrm{SI}=82 \text {. Video } 2 \text { : } \mathrm{TI}=12, \mathrm{SI}=53 .\end{array}$} \\
\hline 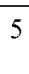 & Line & 28 & 9 & $\mathrm{~N}$ & $\begin{array}{l}\text { Front } \\
\text { line }\end{array}$ & 29 & 5 & \\
\hline
\end{tabular}

Balanced negative disparity and parallax in both sequences Video 1: $\mathrm{TI}=6, \mathrm{SI}=40$. Video 2 : $\mathrm{TI}=13, \mathrm{SI}=44$.

\begin{tabular}{|l|l|l|l|l|l|l|l|l|}
\hline 6 & $\begin{array}{l}\text { Phone } \\
\text { Call }\end{array}$ & 32 & 8 & Y & Soccer & 28.1 & 15 & Y \\
\cline { 2 - 4 }
\end{tabular}

High well-located negative parallax to distributed negative parallax Video 1: $\mathrm{TI}=13, \mathrm{SI}=36$. Video 2 : $\mathrm{TI}=38, \mathrm{SI}=89$.

\begin{tabular}{|c|c|c|c|c|c|c|c|c|}
\hline \multirow[t]{2}{*}{7} & Earth & 34 & 9.7 & $\mathrm{~N}$ & Explosion & 32 & 6 & $\mathrm{~N}$ \\
\hline & \multicolumn{8}{|c|}{$\begin{array}{l}\text { Quick variation of positive parallax and high motion } \\
\text { Video } 1 \text { : } \mathrm{TI}=11, \mathrm{SI}=44 \text {. Video } 2: \mathrm{TI}=22, \mathrm{SI}=20 \text {. }\end{array}$} \\
\hline \multirow[t]{2}{*}{8} & Space & 33 & 15 & $\mathrm{Y}$ & Moon & 25 & 13 & Y \\
\hline & \multicolumn{8}{|c|}{$\begin{array}{l}\text { Fast motion but positive parallax in both videos } \\
\text { Video 1: } \mathrm{TI}=15, \mathrm{SI}=32 \text {. Video } 2 \text { : } \mathrm{TI}=18, \mathrm{SI}=57 \text {. }\end{array}$} \\
\hline \multirow[t]{2}{*}{9} & Shoot & 31 & 5.5 & $\mathrm{~N}$ & Laser & 31 & 5 & $\mathrm{Y}$ \\
\hline & \multicolumn{8}{|c|}{$\begin{array}{l}\text { Fast motion and negative parallax distributed } \\
\text { Video 1: } \mathrm{TI}=64, \mathrm{SI}=19 \text {. Video } 2: \mathrm{TI}=63, \mathrm{SI}=19 .\end{array}$} \\
\hline \multirow{2}{*}{10} & Frontline & 29 & 5.3 & $\mathrm{Y}$ & Line & 28 & 9 & $\mathrm{~N}$ \\
\hline & \multicolumn{8}{|c|}{$\begin{array}{l}\text { Positive parallax in both videos } \\
\text { Video 1: } \mathrm{TI}=13, \mathrm{SI}=44 \text {. Video } 2: \mathrm{TI}=6, \mathrm{SI}=40 \text {. }\end{array}$} \\
\hline 11 & Soccer & 28.1 & 15 & $\mathrm{Y}$ & $\begin{array}{l}\text { Tree } \\
\text { Branch }\end{array}$ & 24.5 & 18 & $\mathrm{~N}$ \\
\hline
\end{tabular}

Low but disperse and quick changing negative parallax. Video 1: $\mathrm{TI}=38, \mathrm{SI}=89$. Video 2 : $\mathrm{TI}=14, \mathrm{SI}=101$.

\begin{tabular}{|c|c|c|c|c|c|c|c|c|}
\hline \multirow[t]{2}{*}{12} & Angel & 22.4 & 14.7 & $\mathrm{Y}$ & Ladder & 27.7 & 7.1 & $\mathrm{~N}$ \\
\hline & \multicolumn{8}{|c|}{$\begin{array}{l}\text { See Section } V \\
\text { Video 1: } T I=7, S I=73 \text {. Video } 2 \text { : } T I=20, S I=50 \text {. }\end{array}$} \\
\hline \multirow[t]{2}{*}{13} & $\begin{array}{l}\text { Palco } \\
\text { Hd1 }\end{array}$ & 12 & 9.5 & $\mathrm{Y}$ & $\begin{array}{l}\text { Tree } \\
\text { Branch }\end{array}$ & 24 & 18 & $\mathrm{~N}$ \\
\hline & \multicolumn{8}{|c|}{$\begin{array}{l}\text { Progressive variance of negative parallax changes to distributed } \\
\text { negative disparity } \\
\text { Video } 1 \text { : } \mathrm{TI}=2 \text {, } \mathrm{SI}=60 \text {. Video } 2 \text { : } \mathrm{TI}=14, \mathrm{SI}=101 \text {. }\end{array}$} \\
\hline 14 & $\begin{array}{l}\text { Space } \\
\text { ship }\end{array}$ & 24 & 17 & $\mathrm{~N}$ & Astronaut & 25 & 7 & $\mathrm{~N}$ \\
\hline & \multicolumn{8}{|c|}{$\begin{array}{l}\text { See Section V } \\
\text { Video 1: } \mathrm{TI}=14, \mathrm{SI}=73 \text {. Video } 2: \mathrm{TI}=9, \mathrm{SI}=96 .\end{array}$} \\
\hline 15 & Muscles & 27 & 14 & $\mathrm{~N}$ & Aphrodite & 25 & 17 & $\mathrm{~N}$ \\
\hline & \multicolumn{8}{|c|}{$\begin{array}{l}\text { Balanced negative parallax in first term of both sequences with medium } \\
\text { motion. } \\
\text { Video } 1 \text { : } \mathrm{TI}=2, \mathrm{SI}=62 \text {. Video } 2 \text { : } \mathrm{TI}=8, \mathrm{SI}=80\end{array}$} \\
\hline 16 & Station & 24 & 13 & $\mathrm{Y}$ & Itaca3d & 25 & 5 & $\mathrm{Y}$ \\
\hline & \multicolumn{8}{|c|}{$\begin{array}{l}\text { See Section } V \\
\text { Video 1: } T I=32, \mathrm{SI}=60 \text {. Video } 2 \text { : } \mathrm{TI}=6, \mathrm{SI}=53 \text {. }\end{array}$} \\
\hline 17 & $\begin{array}{l}\text { Palco } \\
\text { Hd2 }\end{array}$ & 32 & 10 & $\mathrm{Y}$ & $\begin{array}{l}\text { Phone } \\
\text { Call }\end{array}$ & 32 & 8 & $\mathrm{Y}$ \\
\hline
\end{tabular}




\begin{tabular}{|c|c|c|c|c|c|c|c|c|}
\hline \multirow[t]{2}{*}{18} & Chairs & 23 & 10 & $\mathrm{~N}$ & Muscles & 27 & 14 & $\mathrm{~N}$ \\
\hline & \multicolumn{8}{|c|}{$\begin{array}{l}\text { Distributed negative parallax in both videos } \\
\text { Video 1: } \mathrm{TI}=7, \mathrm{SI}=76 \text {. Video } 2 \text { : } \mathrm{TI}=2, \mathrm{SI}=62 \text {. }\end{array}$} \\
\hline \multirow[t]{2}{*}{19} & Hanging & 30 & 6 & $\mathrm{~N}$ & Venus & 23 & 15 & $\mathrm{~N}$ \\
\hline & \multicolumn{8}{|c|}{$\begin{array}{l}\text { Distributed negative parallax in both videos } \\
\text { Video 1: } \mathrm{TI}=13, \mathrm{SI}=76 . \text { Video } 2: \mathrm{TI}=10, \mathrm{SI}=90 \text {. }\end{array}$} \\
\hline \multirow[t]{2}{*}{20} & $\begin{array}{l}\text { Itaca } \\
3 \mathrm{~d}\end{array}$ & 25 & 5 & $\mathrm{Y}$ & $\begin{array}{l}\text { Tree } \\
\text { Branch }\end{array}$ & 24.5 & 18 & $\mathrm{~N}$ \\
\hline & \multicolumn{8}{|c|}{$\begin{array}{l}\text { High synthetic negative parallax combined with motion to distributed } \\
\text { negative parallax } \\
\text { Video } 1: \mathrm{TI}=6, \mathrm{SI}=53 \text {. Video } 2: \mathrm{TI}=14, \mathrm{SI}=101 \text {. }\end{array}$} \\
\hline
\end{tabular}

\section{ANALYSIS OF RESULTS}

Visual discomfort is considered for users scoring 1 or 2 value of MOS scale, and the rest of scores are considered of producing no visual discomfort.

The sequences, in which more than $40 \%$ of the sample complained about the content, were considered as conflictive, as occurred in sequences: $4,12,13,16,17$ and 20. Also, other sequences whose result is over $20 \%$ of the sample have been also considered, as happens with sequences: 3,11 or 18 . These sequences are analyzed in next section, to decide which characteristics of these videos affects to human eye, producing visual discomfort.

It is necessary to understand the scale in Fig. 1 for the interpretation of diagrams of disparity in Fig. 2 to Fig. 6. The shades of grey represent the negative parallax, and black would be the point when hyperstereoscopy occurs, i.e. in order to raise the $3 \mathrm{D}$ experience.

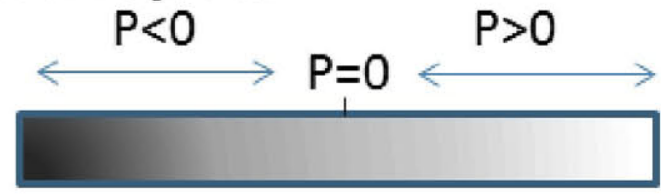

Fig. 1. Scale of levels of parallax necessary to understand disparity diagrams

1) Sequence 12: Transition "Angel" to "Ladder"

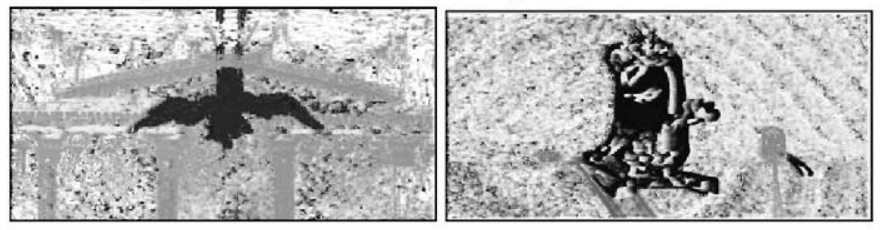

Fig. 2. Disparity diagram of "Angel" and "Ladder"

As shown in disparity diagrams of videos "Angel" and "Ladder", the negative parallax is in the center area of the picture. The abrupt change from negative parallax to a bigger amount of negative parallax pixels produces a visual discomfort in the observer. $40 \%$ of the people give a score that manifests visual discomfort, derived from a change in disparity that affects to the same area in the video sequence. Motion in the first video is medium, but faster in the second, what affects to the final score.

2) Sequence 14: Transition "Spaceship" to "Astronaut"

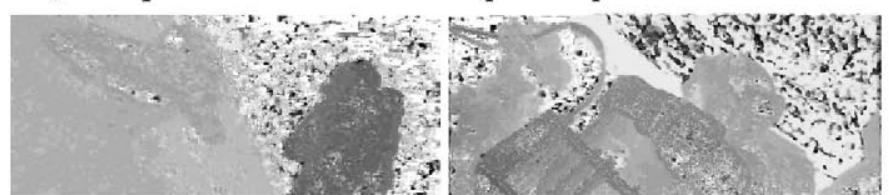

Fig. 3. Disparity diagram of "Spaceship" and "Astronaut"

This sequence was well scored by the observers. Fluctuation from negative parallax in right side of first video to negative/positive combination of parallax in the second one makes the human eye perceive no visual discomfort.

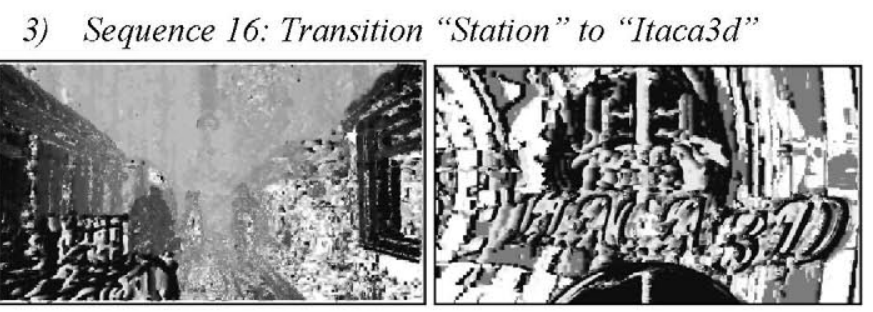

Fig. 4. Disparity diagram of "Station" and "Itaca3d"

The first video of this sequence is a long travelling with high motion and negative in both sides of the picture. On the other side, the second video is affected from hyperstereoscopy, derived from a synthetic modelling, with controlled and negative disparities. Motion and high negative parallax in the transition makes the human eye to assess this sequence as the worst scored in the tests.

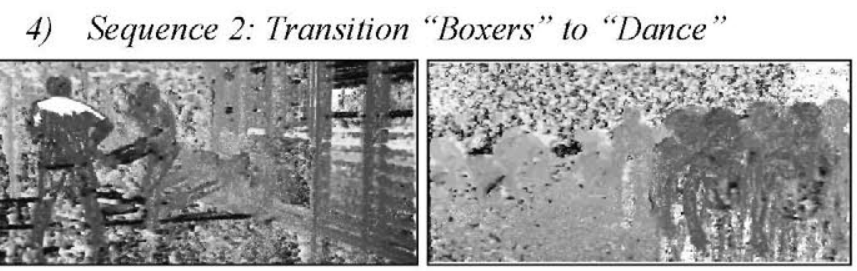

Fig. 5. Disparity diagram of "Boxers" and "Dance"

Moderated negative parallax is included in both videos. In first video the main disparity is found on the left side, changing in the second video to negative parallax in the right side, i.e. the other side.

5) Sequence 4: Transition "Hall" to "Laboratory"
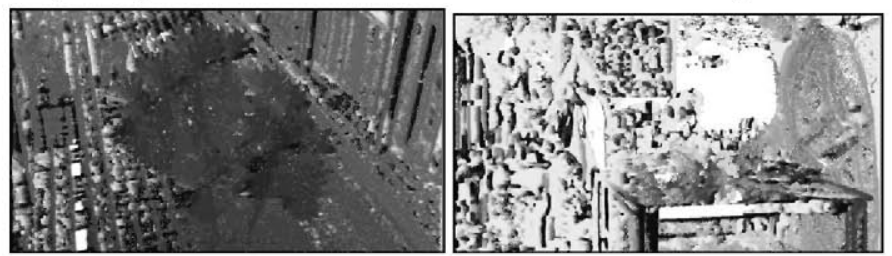

Fig. 6. Disparity diagram of "Hall" and "Laboratory"

The transition in this pair of videos consists of low negative parallax in both videos, in central area for first video and distributed all along the picture in the second one. Video "Laboratory" presents high window violation, what affects to scores from observers.

\section{CONCLUSIONS}

Analyzing the experiment results leads us to the conclusion that the usefulness of subjective tests is high, because it lets seeing the reaction to the changes of disparity when observing a movie. 3D Cinema and 3DTV contents present different levels of parallax between takes and guidelines are necessary in these transitions to help the filmmaker to design images out 
of visual discomfort. Sequences with negative parallax are the most conflictive ones for visual discomfort.

- Motion is a key element of production of visual discomfort, but it is not the only one. When it is combined with sequences with high negative parallax may generate visual discomfort.

- If the negative parallax in hyperstereoscopy is located in different parts of the sequences in the transition, visual discomfort appears less than when located in same areas.

- Fast variation of negative parallax is usually the main source of visual discomfort, especially when the transition is produced to a content with a completely different disparity diagram.

- Only hyperstereoscopy (i.e. pixels with negative parallax with disparities higher than 5) in the sequence is not enough for detecting visual discomfort, it is the transition what provokes the discomfort, as seen in Sequence 20, for example.

\section{ACKNOWLEDGMENT}

The work developed in Universidad Politécnica de Madrid performed in the framework of project TEC2012-38402-C0401 HORFI, which is partially funded by the Spanish Ministry of Science and Innovation. The authors would like to acknowledge the Spanish broadcaster RTVE, the manufacturer company Philips for lending the television used in subjective assessment and University of Nantes for the cession of the stereoscopic database.

\section{REFERENCES}

[1] Qualinet White Paper on Definitions of Quality of Experience (2012). European Network on Quality of Experience in Multimedia Systems andServices (COST Action IC 1003), Patrick Le Callet, Sebastian Möller andAndrew Perkis, eds., Lausanne, Switzerland, Version 1.2, March 2013.

[2] López, J.P., M. Slanina, L. Arnaiz, J.M. Menéndez, "Subjective quality assessment in scalable video for measuring impact over device adaptation," IEEE EuroCon 2013 Zagreb, Croatia, 1-4 July, 978-1-46732232-4 (C) 2013 IEEE, 162-169, Julio 2013

[3] W. Chen, J. Fournier, M. Barkowsky, and P. Le Callet, "Quality of experience model for 3DTV," in Proc. SPIE 8288, Stereoscopic Displays and Applications XXIII, 2012.

[4] Wa James Tam; Speranza, F.; Yano, S.; Shimono, K; Ono, H., "Stereoscopic 3D-TV: Visual Comfort," Broadcasting, IEEE Transactions on , vol.57, no.2, pp.335,346, June 2011

[5] F. Speranza, W.J. Tam, R. Renaud, and N. Hur, "Effect of disparity and motion on visual comfort of stereoscopic images" in Proc. of SPIE, vol 6055, pp. 94-103, 2006

[6] J. Li, M. Barkowsky, and P. Le Callet, "The Influence of Relative Disparity and Planar Motion Velocity on Visual Discomfort of Stereoscopic Videos," in Proceeding of the International Workshop on Quality of Multimedia Experience QoMEX, Mechelen, Belgique, 2011, pp. pp.1-6.

[7] J. Li, M. Barkowsky, and P. Le Callet, "Visual Discomfort is not always proportional to eye blinking rate: Exploring some effects of Planar and In-Depth Motion on 3DTV QoE," in Proceedings of VPQM 2013, Scottsdale, États-Unis, 2013, pp. pp.1-6

[8] Sang-Hyun Cho; Hang-Bong Kang, "Subjective evaluation of visual discomfort caused from stereoscopic 3D video using perceptual importance map," TENCON 2012 - 2012 IEEE Region 10 Conference, vol., no., pp.1,6, 19-22 Nov. 2012

[9] López, J. P., Rodrigo, J. A., Jiménez, D., \& Menéndez, J. M. (2013). Stereoscopic 3D video quality assessment based on depth maps and video motion. EURASIP Journal on Image and Video Processing, 2013(1), 1-14.

[10] Recommendation ITU-T P.910 (v.04/2008). Telecom. Standardization Sector OF ITU "Subjective video quality assessment methods for multimedia applications".

[11] Recommendation ITU-R BT. 2021. "Subjective Assessment of Stereoscopic 3DTV Systems (08/2012)", 2012.

[12] Urvoy, M., Barkowsky, M., Cousseau, R., Koudota, Y., Ricorde, V., Le Callet, P., ... \& García, N. (2012, July). NAMA3DS1-COSPAD1: Subjective video quality assessment database on coding conditions introducing freely available high quality $3 \mathrm{D}$ stereoscopic sequences. In Quality of Multimedia Experience (QoMEX), 2012 Fourth International Workshop on (pp. 109-114). IEEE 